\title{
From the Determination of Sea Emissivity to the Retrieval of Salinity: Recent Contributions to the SMOS mission from the UPC and ICM
}

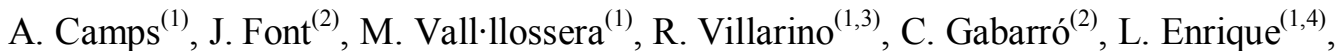

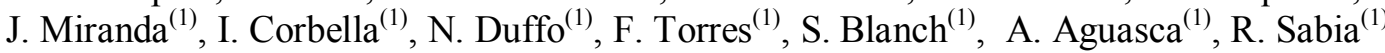 \\ ${ }^{(1)}$ Universitat Politècnica de Catalunya, Campus Nord, D4, 08034 Barcelona, Spain, \\ tel: +34+93.401.60.85, fax: +34+93.401.72.32, email: camps@tsc.upc.es \\ ${ }^{(2)}$ Institut de Ciències del Mar, CMIMA - CSIC, Passeig Marítim, 37-49, 08003 Barcelona, Spain \\ ${ }^{(3)}$ Universitat Autònoma de Barcelona, ET SE QC-2003, 08193 Cerdanyola del Vallès, Spain \\ ${ }^{(4)}$ ICFO - Institut de Ciències Fotòniques, Avda. Canal Olímpic, s/n, 08860 Castelldefels, Spain
}

\begin{abstract}
This work summarizes the main findings of the activities carried out in the past years by the Microwave Radiometry Team at the Technical University of Catalonia (UPC) in the field of sea surface salinity retrieval within the frame of the SMOS mission in collaboration with the Institute of Marine Sciences (ICM/CMIMA-CSIC). They cover the measurement of the dielectric permittivity of the sea water at Lband, the impact on the sea emissivity of the surface roughness (waves, swell, currents, rain ...) and oil spills, and its comparison with numerical models, as well as the development of sea surface salinity retrieval algorithms for SMOS.
\end{abstract}

\section{INTRODUCTION}

The SMOS (Soil Moisture and Ocean Salinity) mission is an Earth Explorer Opportunity Mission from the European Space Agency that will be launched in September 2007. Its goals are twofold: to produce global and frequent maps of soil moisture and ocean salinity to improve the climate modeling. SMOS' single payload is a new type of radiometer called MIRAS: Microwave Imaging Radiometer by Aperture Synthesis. MIRAS operates at L-band (1400-1427 MHz), has multiangular observation capabilities, and can be operated in dualpolarization or full-polarimetric modes. In this band, the sensitivity of the nadir brightness temperature to the sea surface salinity is low $(0.5 \mathrm{~K} / \mathrm{psu}$ for a sea surface temperature of $20^{\circ} \mathrm{C}$, decreasing down to $0.25 \mathrm{~K} / \mathrm{psu}$ at $0^{\circ} \mathrm{C}$ ). Therefore, other variables that influence the brightness temperature signals such as the sea surface temperature, the sea surface roughness (depending on the wind, the swell, the presence of currents, rain, oil spills...) and the presence of foam must be properly accounted for in order to retrieve the SSS with the expected accuracy $(0.1$ psu over 1 month in $100 \mathrm{~km}$ x $100 \mathrm{~km}$ to $200 \mathrm{~km} \mathrm{x} 200 \mathrm{~km}$ boxes). At L-band the brightness temperature $\left(T_{B}\right)$ at $p$-polarization can be simply modeled as:

$$
\begin{aligned}
& T_{B, \text { water }, p}= T_{B, \text { flat }, p}\left(\varepsilon_{r}(f, S S S, S S T)\right)+ \\
&+\sum_{n} \frac{\partial T_{B, \text { rough }, p}(\text { parameter })}{\partial \text { parameter }} \cdot \text { parameter }, \\
& T_{B, p}=(1-F) T_{B, \text { water }}+F T_{B, \text { foam }} .
\end{aligned}
$$

In order to achieve such a stringent accuracy a number of experimental and modeling studies have been carried out in the past years to reduce the uncertainty in the different parameters involved in the modeling of the sea surface brightness temperature: the dielectric constant and its dependence with the temperature $(S S T)$ and the salinity $(S S S)$, the impact of the surface roughness, parameterized in terms of the $10 \mathrm{~m}$ height wind speed $\left(U_{10}\right)$ and/or the significant wave height $(S W H) \ldots$, the surface's foam coverage $(F)$, which is mainly a function of $U_{10}$, but also of the $S S T$ and $S S S$ thought the water viscosity, and the brightness temperature of the foam, which is a function mainly of the foam thickness, the SST and the SSS. These different activities and the main findings are described in the following sections.

\section{FIELd ExPERIMENTs ANd Modelling REsults}

In order to improve the impact of the sea state in the emission models the WISE 2000 and 2001 (WInd and Salinity Experiment) were carried out. The UPC L-band AUtomatic RAdiometer (LAURA) was deployed in REPSOL's Casablanca oil rig (Fig. 1), $40 \mathrm{~km}$ offshore the coasts of Tarragona (Spain), in conjunction with other oceanographic and meteorological instrumentation (Fig. 1) from the Institut de Ciències del Mar (Barcelona, Spain) the Universitat de València (València, Spain), the LODYC (now LOCEAN. Paris, France) and the CETP (Vélizy, France). The main achievements were: a) the determination of the $T_{B}$ dependence with respect to $U_{10}$ and the $S W H$, and b) the retrieval of sea surface salinity from multi-angular polarimetric L-band radiometeric data. Other aspects were addressed in FROG 2003.

The FROG 2003 (Foam, Rain, Oil spills and GPSreflections) was performed at the IRTA facilities at Poble Nou del Delta (Tarragona, Spain) to study specifically the impact of foam, rain, and oil spills in the sea surface emissivity (Figs. 2 and 3). Over a flat water surface rain and oil have a negligible impact, but foam has to be included in the emission model at L-band. 
Finally, in view of the discrepancies existing among different sea water dielectric constant models, newer and accurate measurements specifically at L-band were performed.

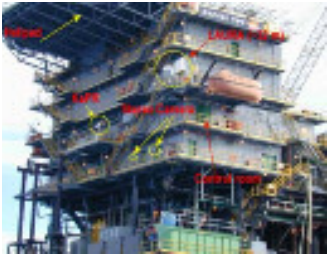

Fig. 1. Instruments deployed for the WISE 2000 and 2001, Repsol's Casablanca Oil Rig (Spain)

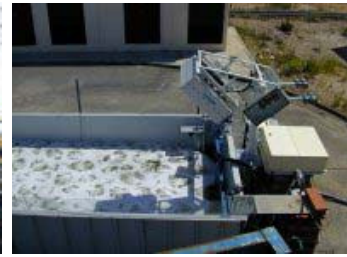

Fig. 2. UPC LAURA radiometer deployed on one side of a $3 \times 7 \mathrm{~m}$ salty water pool with foam generator.

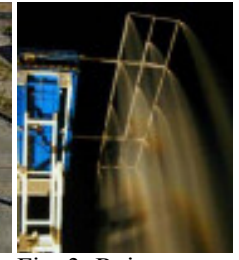

Fig. 3. Rain generator over the salty pool with foam.

\section{A. Dielectric Constant Impact}

Several models for seawater permittivity exist in the literature. Until recently, the most widely used models in remote sensing have been the ones developed by Ellison et al. [1] and by Klein and Swift [2]. Even though the two models are quite similar, the different values of the dielectric constant obtained can produce a bias from about $0.4 \mathrm{~K}$ to $1.1 \mathrm{~K}$ on the predicted $T_{B}$. In [3] a new technique was proposed to accurately measure the complex permittivity of seawater, and results agreed much better with [2] than with [1]. L-band radiometric measurements performed by W. Wilson (JPL) in a salt pond at 25 psu, 35 psu and 40 psu show that [2] and [3] models provide the same $T_{B}$ with the same degree of accuracy $(\sim \pm 0.1$ $\mathrm{K})$ in the range of temperatures from 8 to $32^{\circ} \mathrm{C}[\mathrm{W}$. Wilson, personal communication, 2004].

\section{B. Influence of Sea State}

At higher frequencies, since the short capillary waves react faster to the wind speed than the long gravity waves, the sea state is typically parameterized in terms of $U_{10}$. At L-band, this was our initial thought, as expressed in eqn. (2) [4]:

$$
\begin{aligned}
\Delta T_{h} & \approx 0.25 \cdot\left(1+\theta / 118^{\circ}\right) \cdot U_{10} \\
\Delta T_{v} & \approx 0.25 \cdot\left(1-\theta / 45^{\circ}\right) \cdot U_{10}
\end{aligned}
$$

However, the unexplained large scattering in the measured data (Fig. 4) led us to consider the possibility that other parameters, such as the SWH, were necessary to model it correctly (eqns. 3 [4] and 4 [5]).

$$
\begin{gathered}
\Delta T_{h} \approx 1.09 \cdot\left(1+\theta / 142^{\circ}\right) \cdot S W H \\
\Delta T_{v} \approx 0.92 \cdot\left(1-\theta / 51^{\circ}\right) \cdot S W H \\
\Delta T_{h} \approx 0.12 \cdot\left(1+\theta / 24^{\circ}\right) \cdot U_{10}+0.59 \cdot\left(1+\theta / 50^{\circ}\right) \cdot S W H \\
\Delta T_{v} \approx 0.12 \cdot\left(1-\theta / 40^{\circ}\right) \cdot U_{10}+0.59 \cdot\left(1+\theta / 50^{\circ}\right) \cdot S W H
\end{gathered}
$$
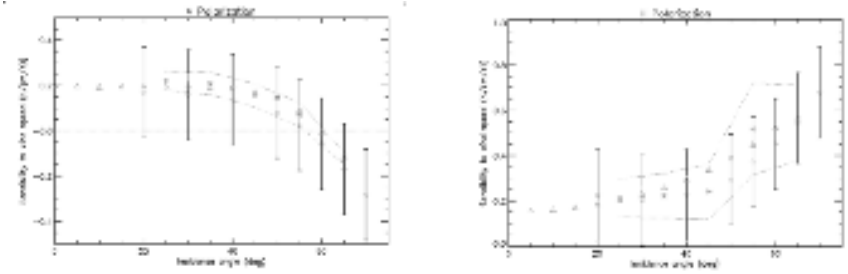

Fig. 4. Inter-comparison between the SSA (Small Slope Approximation: triangles) with Kudryavtsev sea surface spectrum (without foam), the WISE measurements (stars) and Hollinger's measurements (diamonds).

However, if the uncertainty of the brightness temperature sensitivity to wind speed remained only on the order of 0.1 $\mathrm{K} /(\mathrm{m} / \mathrm{s})$ for all incidence angles, then for $U_{10}=10 \mathrm{~m} / \mathrm{s}$, the uncertainty in the brightness temperature would be $\Delta \mathrm{T}_{\mathrm{B}} \approx 1 \mathrm{~K}$. And taking into account the brightness temperature sensitivity to SSS $(0.35-0.8 \mathrm{~K} / \mathrm{psu}$ at $\mathrm{V}$-pol, and $0.20-0.6 \mathrm{~K} / \mathrm{psu}$ at $\mathrm{H}-\mathrm{pol})$, it will translate at $10 \mathrm{~m} / \mathrm{s}$ into a $\Delta S S S$ from 1.2 to $5 \mathrm{psu}$, depending on the polarization and incidence angle.

It is believed part of these fluctuations are related to the so called "L-band brightness temperature fluctuations", on the order of $0.5-1 \mathrm{~K}$, encountered by other groups: D.M. LeVine (NASA Goddard) found oscillations in the $T_{B}$ data derived from ESTAR data at the Gulf stream, and W. Wilson (JPL) found similar fluctuations in data from Monterrey bay (constant incidence angle and flying direction: constant corrections for the galactic noise). Its origin remains unknown, but it has been suggested that they could be originated by a kind of small-scale low-salinity "bubbles" or maybe sudden changes in the roughness, originated by local currents etc.

- Wind direction impact: Azimuthal variations of the measured $T_{B}$ during WISE 2000 at $25^{\circ}$ to $55^{\circ}$ incidence angles at $\mathrm{V}$ - and $\mathrm{H}$-polarizations are within $0.5 \mathrm{~K}$, but they could be due to differences between calibrations, and the authors do not believe there is any measurable azimuthal signature below 10 $\mathrm{m} / \mathrm{s}$, except for an azimuthal scan (same calibration) performed during the most intense storm that happened in the past 25 years. Despite when the measurements were acquired, the wind speed was moderately high $(11 \mathrm{~m} / \mathrm{s})$, the waves were very large $(3 \mathrm{~m}<S W H<5 \mathrm{~m})$, with very large crests that completely destroyed the $7 \mathrm{~m}$ deck of the platform, and seriously damaged the $13 \mathrm{~m}$ deck. In this case, the peak-topeak variations were an order of magnitude larger $(5 \mathrm{~K})$, which cannot be predicted by any combination of numerical model plus sea surface spectrum, which suggests that the wave asymmetry and the effect of foam may be dominant.

- Wave development impact: From the study of an extensive data set of developing sea states a dependence of the longwave spectrum with the inverse-wave-age parameter $\Omega$ was obtained [6,7]. Seas are said to be fully-developed, mature and young when $\Omega_{c}$ has values closed to $0.84,1$ and $>2$, respectively. Figure 5 shows the strong dependence of the unified omnidirectional spectrum, described in [8] (wind speed equal to $15 \mathrm{~m} / \mathrm{s}$ ) with the inverse-wave-age ( $\Omega_{c}$ varying from 0.84 to 5 ).

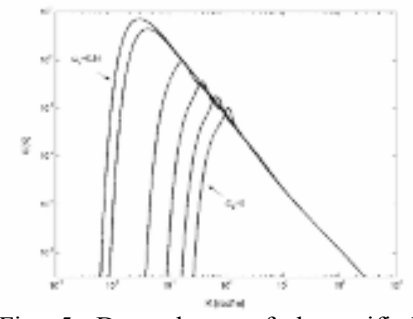

Fig. 5. Dependence of the unified omnidirectional spectrum with the $\Omega_{\mathrm{c}}: 0.84, \quad 1,2, \quad 3,4$ and 5 $\left(U_{10}=15 \mathrm{~m} / \mathrm{s}\right)$.

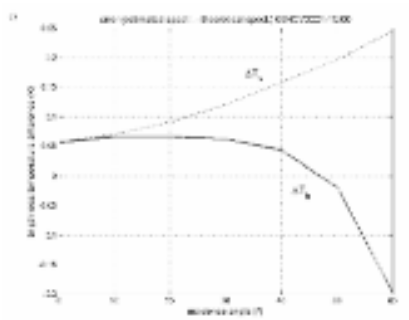

Fig. 6. Swell effect on $\mathrm{T}_{\mathrm{B}}$ : $\Delta T_{v}=T_{v}\left(U_{10}\right)-T_{v}\left(U_{10}\right.$, swell $)$ (dotted) and $\quad \Delta T_{h}=T_{h}\left(U_{10}\right)-T_{h}\left(U_{10}\right.$, swell $)$ (dashed line). 
Differences between fully-developed spectrum and non-fully developed spectrum can be important. Moreover in [9] several $U_{10}$ sequences recorded during WISE 2001 campaigns showed that $U_{10}$ varied almost constantly and that large differences between measured spectra and fully-developed spectra obtained with the measured local wind speed exist, which produced errors in the $T_{B}$ simulations about a fraction of a Kelvin in both polarizations. However, since these differences have opposite sign for $T_{v}$ and $T_{h}$, they could be minimized using the first Stokes parameter $\mathrm{I}=T_{h}+T_{v}$, and the knowledge of the evolution of the local $U_{10}$ could be used to obtain an effective wind to better predict the sea surface spectrum.

- Swell Effects Impact: Durden and Vesecky [10] simulate a swell component by superimposing a Gaussian shaped swell spectrum on the wind sea spectrum, considering that no interaction between these two components exits. The swell spectrum is then modeled by a narrow-band Gaussian process with a two-dimensional roughness spectrum with the following parameters: swell height variance $\left\langle h^{2}\right\rangle$, directional standard deviations $\sigma_{x}$ and $\sigma_{y}$, and swell spectral peak wave numbers $K_{x m}$ and $K_{y m}$, in the directions x and y, respectively, which are not usually coincident with the up-wind and crosswind directions. The presence of swell increases the surface roughness, and if neglected, the error $\Delta T_{v}$ is positive, while $\Delta T_{h}$ is negative. Figure 6 [9] shows this effect when $T_{v}$ and $T_{h}$ are calculated with the SSA/SPM method for the Elfouhaily spectrum with a wind speed $\bar{U}_{10}=11.33 \mathrm{~m} / \mathrm{s}$ and a swell spectrum with the following parameters: $\langle h\rangle=0.28 \mathrm{~m}, \sigma_{\mathrm{x}}=$ $\sigma_{\mathrm{y}}=0.011 \mathrm{~m}^{-1}$, and $K_{x m}=K_{y m}=0.043 \mathrm{rad} / \mathrm{m}$. Resulting $\Delta T_{v}$ and $\Delta T_{h}$ are not negligible at all as compared to the required $\mathrm{T}_{\mathrm{B}}$ accuracy for $S S S$ retrieval.

- Effect of currents: Sea surface currents impact the sea surface roughness spectrum (Fig. 7), which in turn produces a change in $T_{v}$ and $T_{h}$ (Fig. 8). Variations as large as $\sim 0.5 \mathrm{~K}$ are possible if strong currents occur in opposite direction of the wind [11].
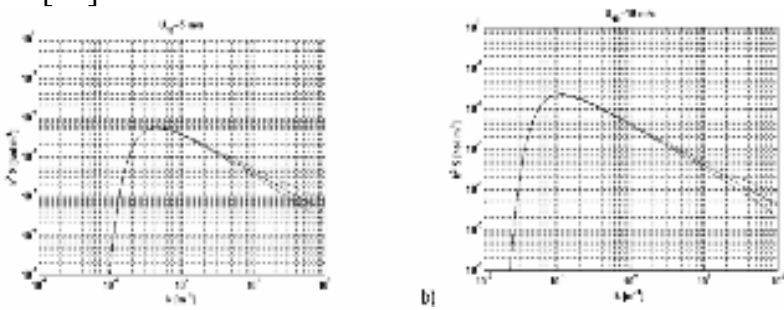

Fig. 7. a) Sea surface slope spectra at a) $U_{10}=5 \mathrm{~m} / \mathrm{s}$, and b) $U_{10}=10 \mathrm{~m} / \mathrm{s}$, for $U_{\text {current }}=3 \mathrm{~m} / \mathrm{s}$ (dashed line), $U_{\text {current }}=0 \mathrm{~m} / \mathrm{s}$ (solid line), and $U_{\text {current }}=-3 \mathrm{~m} / \mathrm{s}$ (dotted line).

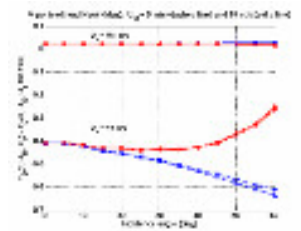

Fig. 8. Brightness temperature variation due to a surface's current of $U_{\text {current }}=$ $-0.1 \mathrm{~m} / \mathrm{s}$ (same direction as wind) and $U_{\text {current }}=+3 \mathrm{~m} / \mathrm{s}$ (opposite direction as wind), for $S S S=35 \mathrm{psu}, S S T=15^{\circ} \mathrm{C}$, and $U_{10}=5 \mathrm{~m} / \mathrm{s}$ (dashed line) and $U_{10}=10$ $\mathrm{m} / \mathrm{s}$ (solid line).
- Effect of rain: The effect of a rain cell within the antenna beam of a down-looking radiometer pointing to the sea surface is three-fold: a) it increases the opacity of the atmosphere and the scattering of the up-welling radiation, b) it creates a surface layer of fresh water, and c) it changes the roughness of the sea surface. The analysis of rain over a flat sea surface was performed by [12], who created artificial rain with raindrop sizes ranging from 2 to $8 \mathrm{~mm}$, falling into a water tank from $13 \mathrm{~m}$ height. The omni-directional rain spectrum derived followed a log-Gaussian law. Figure 9a shows Elfouhaily's wind-induced fully-developed spectrum for different wind speeds, and overlapped the rain-induced ring-waves logGaussian spectrum for different rain rates, concentrated on short-wave spectrum. The net effect of rain is a little increment of the sea surface slopes variance (Fig. 9b).
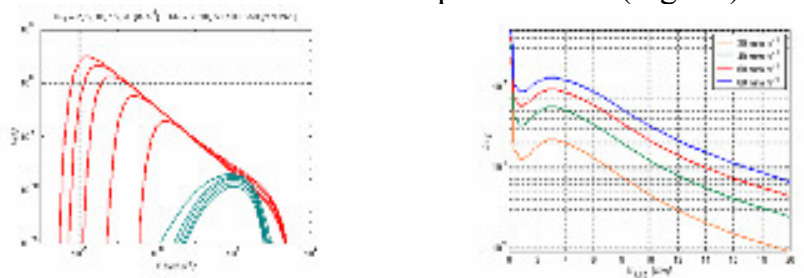

Fig. 9. a) Wind-induced spectrum for wind speeds $5,10,15$ and $20 \mathrm{~m} / \mathrm{s}$ and rain induced spectrum for rain rates 2, 10, 50, 100 and $250 \mathrm{~mm} / \mathrm{hr}$. b) Slope variance increment of sea surface roughness for rain rates of 20,40,60 and 80 $\mathrm{mm} / \mathrm{hr}$ respect to rain free conditions.

During the FROG campaign, measurements of the emission of sea water inside a swimming pool were performed with and without rain and compared to model results [13]. The brightness temperature difference measured with the LAURA radiometer at $H$ - and $V$ - polarizations was nearly negligible, even at extremely high rain intensities $(4000 \mathrm{~mm} / \mathrm{h}$ !). The extrapolated rain-induced $T_{B}$ at nadir and at $1.4 \mathrm{GHz}$ is about $0.075 \mathrm{~K}$ for a rain rate of $160 \mathrm{~mm} / \mathrm{h}$, which is negligible, in agreement with [14], computed with the Small Slope Approximation (SSA) method.

- Oil Spills: Another parameter that may contribute to the $T_{B}$ measurements over the ocean is the presence of oil spills. During FROG 2003, $T_{B}$ was measured mixing fresh and salt water with 0.5 and 1 liter of mineral oil in the pool, to analyze the contribution to the $T_{B}$ of a very thin layer $(47 \mu \mathrm{m})$ of oil over sea water at L-band. It was found that the effect is negligible. This experiment was done in flat sea surface conditions. Other effects of oil spills, such as the increment of the sea water viscosity and the slope variance of the sea surface roughness had not been studied in this experiment, but other measurements concluded that oil spills, which tend to suppress the capillary waves that are steeper, reduce the mean square slope by a factor of 2-3 and, then they reduce the skewness, but leave peakedness unchanged [15].

\section{NuMERICAL EMISSION MODELS For THE SEA}

Numerical methods developed to compute sea emission have been refined with the experimental data gathered during the field experiments described. For ocean applications a software package "epocean" has been developed to compute the sea 
emission with different numerical methods, types of sea surface spectra, types of dielectric constant models, presence or not of swell, foam, rain... [16].

It has been found that beyond asymptotic semi-empirical approaches, both the two-scale model and the SSA model compare well with measured WISE data when they use a surface spectrum model globally multiplied by two, which is an unphysical artificial correction.

\section{Development of Sea Salinity Retrieval Algorithms}

Sea Surface Salinity Retrieval Algorithms using multi-angular radiometric data, have been developed for the multi-incidence angle imaging characteristics of SMOS both from a simulation point of view using SEPS [17], and with experimental data $[4,18,19]$. To do that, an Ocean Salinity - Level 2 Prototype Processor has been developed that can be plugged into SEPS to perform the external calibration and the retrieval of geophysical parameters [17].

The cost function to be minimized has the form

$$
\begin{aligned}
& \mathcal{E}=\frac{1}{\mathrm{~N}_{\text {obs }}} \sum_{n}\left\{\left[\bar{F}_{\text {model }}\left(\theta_{n}, \hat{\vec{P}}\right)-\bar{F}_{\text {data }}\left(\theta_{n}, \vec{P}\right)\right]^{T}+\right.
\end{aligned}
$$

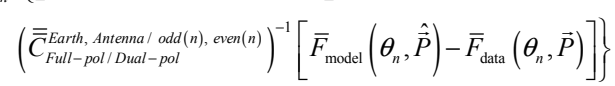

$$
\begin{aligned}
& +\frac{\left(S S T-S S T_{\text {ref }}\right)^{2}}{\sigma_{\mathrm{SST}}^{2}}+\frac{\left(U_{10}-U_{10_{\text {ref }}}\right)^{2}}{\sigma_{\mathrm{U}_{10}}^{2}},
\end{aligned}
$$

where $\mathrm{N}_{\mathrm{obs}}$ is the number of measurements acquired at the

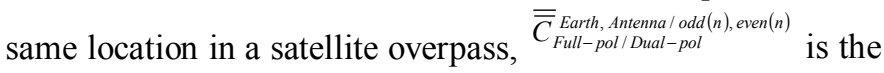
error covariance matrix that depends on the SMOS operation mode, the reference frame, and the pixel position in the field of view [20]. In turn, $\bar{F}_{\text {model } / \text { data }}\left(\theta_{n}, \vec{P}\right)$ is a vector that contains the modelled and measured observables $(\vec{P})$, and its structure depends on the formulation of the retrieval problem. The last two terms are restrictions to the $S S T$ and $U_{10}$ around reference values given by some auxiliary data sets, with a given variance. No restrictions are added to the SSS since it was found that they were too restrictive and forced the solution to the reference value [21, WP1400].

To minimize the impact of antenna cross-polar errors, and imperfect Faraday rotation correction (which may be not necessarily homogeneous over the SMOS pixel), the UPC team first proposed in 2001 the use of the first Stokes parameter $I$ computed in the antenna reference frame $\left(T_{x}, T_{y}\right)$ to retrieve sea surface salinity:

$$
\bar{F}\left(\theta_{n}, \vec{P}\right)=\left[\mathrm{I}\left(\theta_{n}, \vec{P}\right)\right]^{T}=\left[T_{x}\left(\theta_{n}, \vec{P}\right)+T_{y}\left(\theta_{n}, \vec{P}\right)\right]^{T} .
$$

This technique benefits from the higher radiometric sensitivity of the instrument in the dual-polarization mode, and presents just a small degradation (1.1-1.2) on the retrieval performance due to the smaller number of data (two measurements are added to get one: $\mathrm{I}=T_{x}+T_{y}$ ).

The main conclusions of a recent study [21, WP1400] carried out to analyze the impact of the use of different auxiliary data

sets on an ideal SMOS/MIRAS instrument just limited by thermal noise are :

- $\quad$ In one overpass the rms SSS error is typically around 1 $p s u$ (varying depending on the auxiliary data used) increasing up to $4 \mathrm{psu}$ or more at swath edges, in agreement with $[17,20]$. A bias appears in the measurements and must be corrected for by using groundtruth data (e.g. buoys or drifters).

- Monthly temporally-averaged retrieved SSS at pixel level provides a rms error about 0.33-0.55 psu, depending on the auxiliary dataset used, and the use of different sources of auxiliary data for SST has a minimum impact in the SSS retrieval.

- $\quad$ Spatio-temporally averaged retrieved SSS in a period of 30 days and in $1^{\circ} \times 1^{\circ}$ boxes, leads to rms retrieved SSS error between $0.055-0.309 \mathrm{psu}$, and in $2^{\circ} \times 2^{\circ}$ boxes between $0.032-0.291 \mathrm{psu}$.

It has been also found that:

- The difference between the direct and inverse models (used to create the $T_{B}$ s and in the retrieval, respectively), are the responsible of the introduction of the bias, different models leading to different biases.

- The radiometric noise does not seem to play a crucial role, since apparently its effect is mostly filtered out in the spatio-temporal averaging procedure, and

- $\quad$ Apart from the intrinsic auxiliary $U_{10}$ and $S S T$ difference; additional residual error sources lie in biased auxiliary wind field mean values and in strong zonal inhomogeneities between wind fields.

An example of one overpass, one-month temporal averaging and one-month and $1^{\circ} \times 1^{\circ}$ spatio-temporal averaging are presented in Figs. 10-12.

Other studies [17] have shown that, without auxiliary data and after spatio-temporal averaging (30 days, $1^{\circ} \times 1^{\circ}$ ) the SSS rms error ranges from $0.2 \mathrm{psu}$ at the Equator to $0.7 \mathrm{psu}$ in Polar regions.

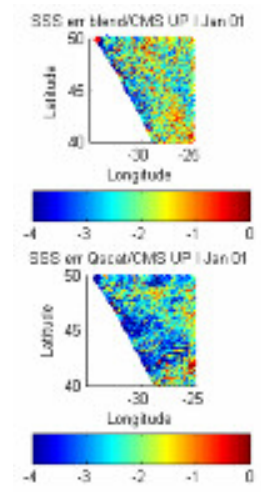

Fig. 10. Sample simulated salinity retrieval error using I corresponding to January $1 \mathrm{st}$, 2003 using different auxiliary data sets in a $10^{\circ} \times 10^{\circ}$ box (ascending orbit).

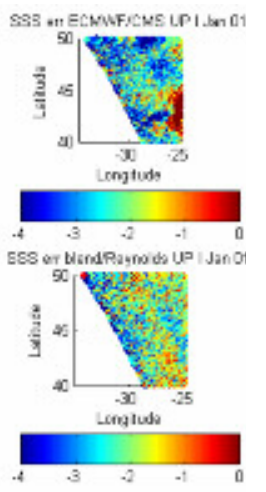

Fig. 12 . Monthly and $1^{\circ} \times 1^{\circ}$ spatial averaging on retrieved SSS using I. 


\section{CONCLUSIONS}

This work has summarized the main findings of the activities carried out in the past years by the Microwave Radiometry Team at the Technical University of Catalonia (UPC) in the field of sea surface salinity retrieval within the frame of the SMOS mission in collaboration with the Institute of Marine Sciences (ICM/CMIMA-CSIC). The new sea water dielectric constant measurements and its comparison with other existing models and measurements have been performed, as well as the study of the impact on the brightness temperature of sea state, parameterized in terms of $U_{10}$, the $S W H$, as well as the effect of wave development, swell, currents, rain, and oil spills.

SSS retrieval algorithms using multi-angular radiometric data tailored to the SMOS imaging configurations have been developed and simulation results have been presented on the performances that could be achieved in different scenarios.

Future research lines include the processing of new sea water dielectric constant measurements and the systematic exploitation of the L2-prototype processor in conjunction with SEPS 4.0 to analyze the best SSS retrieval configuration for SMOS.

\section{ACKNOWLEDGMENT}

These work has been supported by ESA Projects ESA, ESTEC Contract No 141888/00/NL/DC, CCN-1 and CCN2, ESA Contract 18176/04/NL/CB, and Spanish Research projects and EU FEDER CICYT TIC 99-1050-C03-01, MCYT TIC200204451-C02-01, PNE-009/2001-C-02, ESP2002-11648-E, and ESP2004-00671.

\section{REFERENCES}

[1] Ellison, W., A. Balana, G. Delbos, K. Lamkaouchi, L. Eymard, C. Guillou and C. Prigent, "New Permittivity Measurements of Sea Water", Radio Science, Vol 33, No 3, pp 639-648, 1998

[2] Klein, L.A., and Swift, C.T., "An Improved Model for the Dielectric "Constant of Sea Water at Microwave Frequencies", IEEE Journal of Oceanic Engineering., OE-Vol 2, No 1, pp 104-111,1977

[3] Blanch S., and A. Aguasca, "Seawater Dielectric Permittivity Model From Measurements at L-Band", IGARSS 2004, Alaska, September 2004

[4] Camps, A., Font, J., Vall-llossera, M., Gabarró, C., Villarino, R., Enrique, L., Miranda, J., Corbella, I., Du o, N., Torres, F., Blanch, S., Arenas, J., Juli a, A., Etcheto, J., Caselles, V., Weill, A., Boutin, J., Contardo, S., Niclós, R., Rivas, R., Reising, S., Wursteisen, P., Berger, M., and Martín-Neira, M., "The WISE 2000 and 2001 Campaigns in Support of the SMOS Mission: Sea Surface L-band Brightness Temperature Observations and their Application to Multi-Angular Salinity Retrieval," IEEE Transactions on Geoscience and Remote Sensing, Vol.42, nº 4., pp. 804-823, April 2004

[5] Gabarró, C., J. Font, A. Camps, M. Vall-llossera, and A. Julià, “A new empirical model of sea surface microwave emissivity for salinity remote sensing," Geophysical Research Letters, Vol. 31, L01309, doi: 10.1029/2003GL018964,2004,14 January 2004.

[6] Donelan, M.A., J. Hamilton and W. H. Hui, "Directional spectra of wind generated waves," Philos. Trans. R. Soc. London, Ser. A, 315, pp. 509$562,1985$.

[7] Dobson, F., W. Perrie and B. Toulany, "On the deep-water fetch laws for wind-generated surface gravity waves," Atmos. Ocean, 27(1), pp. 210-236, 1989.
[8] Elfouhaily, T., B. Chapron, K. Katsaros, and D. Vandermark, "A unified directional spectrum for long and short wind-driven waves," J. Geophys. Res., vol. 102, no C7, pp. 15781-15796, July 15, 1997

[9] Miranda, J.J., M. Vall-1lossera, A. Camps, N. Duffo, I. Corbella, and J. Etcheto, "Sea state effect on the sea surface emissivity at L-band," IEEE Transactions on Geoscience and Remote Sensing, Vol. 41, No. 10, pp. $2307-2315$, October 2003

[10] Durden, S.L. and J.F. Vesecky, "A physical radar cross-section model for a wind-driven sea with swell," IEEE Journal of Oceanic Engineering, Vol OE-10, No 4, pp.445-451, Oct. 1985

[11] Camps, A., M. Vall-1lossera, J. Miranda, "Sea Surface Brightness Temperature At L-band: Impact Of Surface Currents," Proceedings of the IGARSS 2004, Anchorage, Alaska, USA, 20-24 September 2004

[12] Craeye, C., P.W. Sobieski, L. F. Bliven, "Scattering by artificial wind and rain roughned water surfaces at oblique incidences," Int. Journal Remote Sensing, Vol. 18, No 10, pp 2241-2246, 1997.

[13] Camps, A., M. Vall-llossera, R. Villarino, N. Reul, B. Chapron, I. Corbella, N. Duffo, F. Torres, J. J. Miranda, R. Sabia, A. Monerris, and R. Rodríguez, "The Emissivity of Foam-Covered Water Surface at LBand: Theoretical Modeling and Experimental Results From the Frog 2003 Field Experiment," IEEE Transactions On Geoscience And Remote Sensing, Vol. 43, No. 5, pp 925-937, May 2005

[14] Miranda, J., M. Vall-llossera, R. Villarino, A. Camps, "Sea state and rain effects in the sea surface emissivity at L-Band," Proc. of the First Results Workshop on WISE/LOSAC/EuroSTARSS Campaigns, ESA, pp. 17-26, France, March 2003

[15] Cox, C. S., and W. H. Munk, "Statistics of the sea surface derived from Sun glitter," J. Mar. Res., 13, 198-227, 1954

[16] Vall-llossera, M., J. Miranda, A. Camps, R. Villarino, "Sea Surface Emissivity Modelling at L-Band: An Inter-Comparison Study," EuroSTARRS, WISE and LOSAC First results Workshop, ESA SP-525 (ISBN 92-9092-835-2), pp. 143-153, May 2003, ed. ESA Publications Division

[17] Camps, A., M. Vall-1lossera, L. Batres, F. Torres, N. Duffo, I. Corbella, "Retrieving sea surface salinity with multiangular L-band brightness temperatures: Improvement by spatiotemporal averaging," Radio Sci., Vol. 40, No. 2, RS2003 10.1029/2004RS003040, 31 March 2005

[18] Camps, A., J. Font, J. Etchetto, V. Caselles, A. Weill, I. Corbella, M. Vall-1lossera, N. Duffo, F. Torres, R. Villarino, L. Enrique, A. Julià, C. Gabarró, J. Boutin, E. Rubio, S.C. Reising, P. Wursteisen, M. Berger, M. Martín-Neira, "Sea Surface Emissivity Observations at L-band: First Results of the Wind and Salinity Experiment WISE-2000," IEEE Transactions on Geoscience and Remote Sensing, Vol. GRS-40, No. 10, pp. 2117-2130, October 2002

[19] Gabarró, C., M. Vall-1lossera, J. Font, A. Camps, "Determination of sea surface salinity and wind speed by L-band microwave radiometry from a fixed platform," International Journal of Remote Sensing, Vol. 25 , No 1, pp. 111-128, January 2004

[20] Camps, A., M. Vall.llossera, N. Duffo, F. Torres, I. Corbella, "Performance Of Sea Surface Salinity and Soil Moisture Retrieval Algorithms With Different Ancillary Data Sets in 2D L-Band Aperture Synthesis Interferometric Radiometers," IEEE Transactions on Geoscience and Remote Sensing, Vol.43, n.5, May 2005, pp 1189-1200.

[21] "Synergetic Aspects and Auxiliary Data Concepts for Sea Surface Salinity Measurements from Space," ESA ESTEC 18176/04/NL/CB, Final Report, January 2006 ftp://ftp.estec.esa.nl/ftp/pub/vr/VRO/GS Study 18176 FR.pdf 